\title{
POLA KERUANGAN BUDAYA OLOH SALAM MASYARAKAT KALIMANTAN TENGAH DENGAN PENDEKATAN GEOSPASIAL
}

\author{
Evi Fitriana ${ }^{1}$ \\ 1Jurusan Pendidikan Geografi FKIP Universitas PGRI Palangka Raya \\ Jl. Hiu Putih KM 7, Palangka Raya \\ Email: eviza27@gmail.com
}

\begin{abstract}
Abstrak
Islam masuk ke Indonesia mampu beradaptasi dengan kebudayaan lokal. Proses penyampaian islam dengan cirinya yang apresiatif dengan budaya lokal serta memihak dengan warga setempat menyebabkan Islam diterima sebagai agama baru. Penelitian ini bertujuan untuk memetakan budaya Oloh Salam, kebudayaan lokal suku Dayak, sejarah persebaran islam di Kalimantan Tengah dan deskripsi budaya Oloh Salam. Oloh salam adalah orang-orang Dayak yang memilih memeluk agama Islam namun masih terdapat sisa-sisa kepercayaan primitif tercampur dengan unsur-unsur agama Islam. Beberapa aspek budaya oloh salam yang khas meliputi upacara kehidupan disebut juga gawi belum dan upacara kematian atau gawi matei serta aspek seni. Kekhasan ini merupakan keunikan tersendiri bila ditinjau berdasarkan letak geografisnya yaitu di Pulau Kalimantan. Metode penelitian menggunakan studi pustaka, data dan informasi kemudian diolah mengunakan pendekatan geospasial dengan overlay peta. Hasil overlay menjelaskan pola keruangan budaya Oloh Salam membentuk pola memanjang sungai dan pantai. Hal ini menunjukkan bahwa persebaran islam dimulai dari pesisir kemudian berlayar melalui sungai untuk memperluas ajaran islam khususnya di Kalimantan Tengah.
\end{abstract}

Kata kunci: budaya, Oloh Salam, pola keruangan

\begin{abstract}
Islam entry into Indonesia is able to adapt to local culture. The process of conveying Islam with cultural approach makes Islam readily accepted by local communities. Islam that is appreciative with local culture and taking sides with local people causes Islam to be accepted as a new religion. This Study aims to determine the spatial pattern Oloh Salam culture, local culture of Dayak, history of the Islamic spread in Central Kalimantan, and definition of Oloh Salam culture. Dayak's culture in Central Kalimantan who has follow Islamic religion is called Oloh Salam. The conversion process of Dayak etnic from their religion become Islam is the impact of the opening of river routes from upstream to downstream. Some typical cultural aspects include the ceremony of life is also called gawi and death ceremony or gawi matei. The research method used in the literature study, data and information obtained then processed using geospatial approach by overlaying the map. The results showed that the spatial pattern of the Oloh Salam culture formed a longitudinal pattern of rivers and beaches. This proves that, the spread of Islam began in the coastal areas then sailed through the river channel to expand the spread of Islam to spread to remote areas especially in Central Kalimantan.
\end{abstract}

Key words: spatial pattern, culture, Oloh Salam 


\section{PENDAHULUAN}

Indonesia merupakan salah satu Negara kepulauan yang kaya akan budaya, masing-masing pulau yang terdiri dari beberapa wilayah memiliki kebudayaan tersendiri sesuai dengan lingkungan dan kondisi alam yang ditinggali. Kebudayaan adalah semua hasil karya, rasa dan cipta masyarakat dalam rangka kehidupan masyarakat yang dijadikan milik diri manusia dengan belajar (Koentjaraningrat, 1981). Jadi budaya adalah sesuatu hal yang pernah dilakukan masyarakat secara turun temurun dan sangat bersangkutan dengan adat istiadat masyarakat.

Kalimantan adalah pulau terbesar kedua di Indonesia setelah Papua yang memiliki penduduk lokal yang disebut dengan suku Dayak. Suku Dayak di Kalimantan tersebar di berbagai daerah seperti di Serawak, Malaysia, Kalimantan Utara, Kalimantan Timur, Kalimantan Selatan, dan Kalimantan Barat dengan keanekaragaman bahasa dan pola hidup. Kebanyakan orang Dayak mendiami daerah pedalaman yang memiliki hutan yang masih lebat serta di sepanjang tepi aliran sungai-sungai besar. Sungai merupakan hal yang sangat penting untuk menunjang kebutuhan hidup sehari-hari serta digunakan untuk jalur transportasi antar satu desa ke desa yang lainnya.

$$
\text { Masuknya agama Islam di }
$$

Nusantara tidak dalam waktu bersamaan, begitu juga dengan masuk dan berkembangnya agama Islam ke daerahdaerah Kerajaan yang pada waktu itu masih dikuasai oleh Kerajaan Hindu Budha yang memiliki politik dan sosial budaya yang berbeda dengan islam. Masuk dan tersebarnya agama Islam di Nusantara hingga saat ini belum diketahui secara pasti oleh para sejarawan. Dalam buku Sejarah Masuk dan Berkembangnya Islam di Indonesia, mengatakan bahwa masuknya Islam sudah ada sejak abad ke-7 dan ke-8 Masehi (Hamka, 1982). Penyebaran agama
Islam banyak dilakukan oleh orang-orang Arab yang datang dengan tujuan utama adalah untuk melakukan perdagangan dan sekaligus menyebarkan agama islam (Abduh, 1985).

Wilayah yang pertama kali disinggahi oleh para pedagang Arab di wilayah Nusantara adalah pesisir Sumatera. Beranjak dari proses perdagangan di pesisir Sumatera inilah kemudian awal mula munculnya kerajaan-kerajaan yang bercorak Islam. Hal ini tidak terlepas karena adanya proses inkulturasi yang dilakukan oleh para pedagang Arab melalui perdagangan dan pernikahan dengan pribumi yang kebanyakan nonmuslim. Berdasarkan proses ini melahirkan kerajaan-kerajaan bercorak islam yang semakin berkembang. Diperkirakan pada abad ke-13 M, kerajaan yang pertama kali bercorak islam di nusantara adalah Samudra Pasai, pesisir timur laut Aceh, dan Kabupaten Lhok Seumawe atau Aceh Utara (Kartodirdjo, 1975:2)

Islam lebih dahulu berkembang di daerah Banjarmasin, Kalimantan Selatan yang dibawa oleh para pedagang dari Arab yang kemudian terjadi akulturasi antara budaya lokal dengan Islam (Buseri, 2009). Budaya masyarakat Dayak di Kalimantan Tengah yang telah memeluk Islam adalah budaya Oloh Salam yang merupakan sebutan internal orang-orang Dayak yang masih memeluk agama helo atau agama leluhur untuk menyebut saudara sesukunya yang telah masuk islam (Adam, 2007). Proses konversi agama suku Dayak dari agama helo (kaharingan) ke islam merupakan sebuah imbas dari terbukanya jalur-jalur sungai yang panjang dari hulu sampai hilir (Rafiq, 2013). Terdapat kecenderungan pembentukan pola perilaku kehidupan sosial budaya Dayak Islam yang bersifat khas. Sebagaimana yang terlihat di berbagai dimensi kehidupan seperti dalam gawi belum berupa upacara kelahiran, pengobatan, perkawinan, sedekah laut; 
gawi matei berupa upacara kematian. Untuk itu perlu diketahui pola keruangan persebaran budaya Oloh Salam yang ada diKalimantan Tengah.

Pembentukan suatu lingkungan permukiman pada dasarnya sangat ditentukan oleh berbagai faktor, diantaranya adalah budaya masyarakat setempat. Bagaimana individu berhubungan dengan keluarga dan lingkungan sekitarnya sudah tentu berbeda antara satu budaya dengan budaya lainnya, selanjutnya bagaimana ruang itu ditata dan dirancang sangat tergantung pada pandangan hidup masing-masing (Dansby, 1993). Salah satu bagian yang penting untuk diketahui dalam hubungan antara manusia dengan lingkungannya adalah pemahaman tentang bagaimana ruang diorganisasikan tergantung pada tujuan manusia itu sendiri (Aspinall, 1993).

Dalam konteks budaya berkait dengan ruang permukiman, Yi-Fu Tuan (1977) menyatakan untuk menjelaskan makna dari organisasi ruang dalam konteks tempat (place) dan ruang (space) harus dikaitkan dengan budaya. Budaya sifatnya unik, antara satu tempat dengan tempat lain bisa sangat berbeda maknanya. Selanjutnya manusia akan mengekspresikan dirinya pada lingkungan dimana dia hidup, sehingga lingkungan tempat tinggalnya akan diwujudkan dalam berbagai simbolisme sesuai dengan budaya mereka. Bagaimana manusia memilih tempat tertentu dan menggunakan berbagai kelengkapan, ataupun berbagai cara untuk berkomunikasi pada dasarnya merupakan "bahasa" manusia. Pola ini tidaklah semata dilihat dalam kaitan dengan lingkungan semata, akan tetapi pada waktu yang bersamaan juga merupakan perwujudan budaya mereka (Locher, 1978).

Berdasarkan kajian budaya Sasak di Desa Puyung nampak bahwa determinasi budaya muncul pada ruang permukiman, dan selanjutnya dapat menunjukkan adanya struktur ruang. Melalui kajian terhadap kepercayaan masyarakat Puyung, gambaran makro kosmos tetap nampak pada orientasi rumah dan bangunan yang mengarah ke Gunung Rinjani (Sasongko, 2005). Penelitian ini membahas tentang budaya lokal masyarakat Dayak, persebaran Islam di Kalimantan Tengah, budaya Oloh Salam, dan pemetaan pola keruangan budaya Oloh Salam di Kalimantan Tengah.

\section{METODE PENELITIAN}

Metode penelitian yang digunakan untuk menganalisis pola keruangan budaya Oloh Salam masyarakat Kalimantan Tengah ditinjau dari pendekatan geospasial ini menggunakan studi kepustakaan berupa penelaahan dan analisa buku, artikel, sumber-sumber lokal, dokumen, serta artikel dari jurnal yang mendukung. Data dan informasi yang diperoleh diolah menggunakan pendekatan geospasial dengan melakukan overlay peta. Hasil overlay peta menjelaskan tentang pola keruangan budaya Oloh Salam di Kalimantan Tengah. Adapun metode pedekata geospasial yang digunakan dalam penulisan ini melalui tahap-tahap berikut ini:

1. Tahap pertama adalah mencari kebutuhan sistem, yaitu:

- Mempelajari Software ArcGis dengan prinsip-prinsip kerjanya.

- Mencari dan mengumpulkan data tentang persebaran agama Islam yang didapatkan dari Dinas Kebudayaan, Kementerian Agama, perpustakaan daerah, jurnal / artikel yang berhubungan dengan kebudayan Oloh Salam.

2. Tahap kedua adalah melakukan analisis perancangan sistem yang di antaranya sebagai berikut:

- Melakukan perancangan sistem sesuai data dan aturan yang ditetapkan. 
3. Tahap ketiga adalah melakukan pembuatan aplikasi sistem yang telah direncanakan, diantaranya sebagai berikut:

- Menyiapkan hardware dan software sebagai teknologi yang digunakan.

- Melakukan pemrosesan data pada peta sehingga siap digunakan.

4. Tahap keempat adalah tahap pengujian hasil untuk melihat apakah sistem yang dibuat sudah atau belum sesuai dengan kebutuhan.

5. Tahap kelima adalah membuat dokumentasi untuk tiap tahapan proses di atas.

\section{HASIL DAN PEMBAHASAN \\ Budaya Lokal Masyarakat Dayak Kalimantan Tengah}

Pada saat benua Asia dan pulau Kalimantan merupakan bagian nusantara masih menyatu, yang memungkinkan ras mongoloid dari Asia mengembara melalui daratan dan sampai di Kalimantan dengan melintasi pegunungan yang sekarang disebut pegunungan "Muller-Schwaner". Suku Dayak merupakan penduduk Kalimantan yang sejati (Kompasiana, 2013). Namun setelah orang-orang Melayu dari Sumatera dan Semenanjung Malaka datang, mereka makin lama makin mundur ke dalam. Suku Dayak hidup terpencar-pencar di seluruh wilayah Kalimantan, mereka menyebar menelusuri sungai-sungai hingga ke hilir dan kemudian mendiami pesisir pulau Kalimantan. Suku ini terdiri atas beberapa suku yang masing-masing memiliki sifat dan perilaku berbeda.

Dalam tradisi lisan Dayak, sering disebut "Nansarunai Usak Jawa", yakni sebuah kerajaan Dayak Nansarunai yang hancur oleh Majapahit, yang diperkirakan terjadi antara tahun 1309-1389 (Ukur, 1971). Kejadian tersebut mengakibatkan suku Dayak terdesak dan terpencar, sebagian masuk daerah pedalaman. Arus besar berikutnya terjadi pada saat pengaruh Islam yang berasal dari kerajaan Demak bersama masuknya para pedagang Melayu (sekitar tahun 1608). Sejak awal abad V bangsa Tionghoa telah sampai di Kalimantan. Pada abad XV Raja Yung Lo mengirim sebuah angkatan perang besar ke selatan (termasuk Nusantara) di bawah pimpinan Chang Ho, dan kembali ke Tiongkok pada tahun 1407, setelah sebelumnya singgah ke Jawa, Kalimantan, Malaka, Manila dan Solok. Pada tahun 1750, Sultan Mempawah menerima orangorang Tionghoa (dari Brunei) yang sedang mencari emas. Orang-orang Tionghoa tersebut membawa juga barang dagangan diantaranya candu, sutera, barang pecah belah seperti piring, cangkir, mangkok dan guci (Kertodipoero, 1963).

Kalimantan Tengah memiliki etnisitas yang relatif berbeda dibandingkan dengan Kalimantan Barat dan daerah lainnya. Mayoritas ethnis yang mendiami Kalimantan Tengah adalah etnis suku Dayak Ngaju, Ot Danum, Maanyan, Dusun, dan lain sebagainya. Sedangkan agama yang mereka anut sangat variatif (Darmadi, 2016).

\section{Persebaran Islam di Kalimantan Tengah}

Islam masuk di Kalimantan sekitar abad-13 bersamaan dengan masuknya Islam secara institusional sebagaimana yang terdapat di Aceh tepatnya pada tahun 1292 saat pengukuhan Sultan Malikussaleh. Hal ini dapat dilacak pada penggunaan berbagai kosakata budaya Parsi yang tersebar hampir menyeluruh di wilayah Aceh dan Kalimantan antara lain bandar, barzanji, tajin, saparan, sjah. Penggunaan sjah di Kalimantan khususnya dapat dilacak sejak berdirinya kerajaan pertama di Kalimantan Selatan yaitu Nagara Dipa yang dibangun oleh Ampu Djatmaka sebagai Raja pertama dengan gelar Maharadja. Periode Nagara Dipa ini bersamaan dengan periode Majapahit dan pada masa kemudian disebutkan, dalam pupuh XIII Negara Kertagama, sebagai salah satu wilayah Majapahit. Para hulubalang kerajaan Nagara Dipa menyebut Ampu Djatmaka dengan panggilan Sjah Alam seperti dapat dilihat dalam Hikajat Bandjar (Ras, 1968). Fakta lain masuknya Islam di 
Kalimantan Tengah juga dikaji dalam mitologi Dayak yang menceritakan adanya putri Campa dalam kaitannya dengan penciptaan tajau atau belanga(Graaf, 1974).

\section{Islam Masuk Di Wilayah Mandomai}

Islam masuk ke daerah Mandomai melewati jalur perniagaan, pedagang dari daerah Kuin, Bandarmasih yang terlebih dahulu memeluk Agama Islam mensyiarkan Islam sambil melakukan aktifitas perdagangannya. Islam masuk ke daerah Mandomai abad ke-18, para penghuni "huma hai" pun tertarik dengan ajaran Islam yang menurut mereka sangat relevan dengan kehidupan manusia, penyebaran Islam begitu pesat di Mandomai, hal ini terbukti dari adanya pembauran budaya setempat dengan corak budaya Islam, seperti nisan makam yang berbentuk tinggi seperti sapundu (titian menuju surga menurut ajaran agama Kaharingan) berukirkan kaligrafi arab di sebuah makam seorang penghuni "huma hai" yaitu Oedjan.

Perkembangan islam di Mandomai berkaitan erat dengan seorang tokoh di "huma hai" yaitu Oedjan ini, ayah Oedjan berasal dari daerah Palingkau, tepatnya Doesoen Timoer Patai, Oedjan adalah anak dari Damboeng Doijoe yang juga disebut seorang Temenggung Madoedoe sepupu dari Soetawana ayah Soetarnoe di Tamiang Layang, Temenggung Madoedoe ini anak dari Djampi yang merupakan kakek dari Oedjan yang sudah memeluk Ajaran Islam. Oedjan menikah dengan gadis keturunan Portugis yang bernama Makau (Saleh), dari perkawinannya ini di anugerahi 9 anak yaitu Sahaboe, Oemar, Aloeh, Galoeh, Soci, Ali, Esah, Tarih, dan Njai.

\section{Islam Masuk di Wilayah Kotawaringin}

Ulama yang berjasa dalam menyebarkan ajaran Islam di wilayah Kotawaringin adalah Kiai Gede, seorang ulama asal Jawa yang diutus oleh Kesultanan Demak untuk menyebarkan ajaran Islam di pulau Kalimantan. Kedatangan Kiai Gede tersebut ternyata disambut baik oleh Sultan Mustainubillah. Kiai Gede kemudian ditugaskan menyebarkan Islam di wilayah Kotawaringin sekaligus membawa misi untuk merintis kesultanan baru.

Berkat jasa-jasanya menyebarkan Islam dan membangun wilayah Kotawaringin, Sultan Mustainubillah menganugerahi jabatan kepada Kiai Gede sebagai Adipati di Kotawaringin dengan pangkat Patih Hamengkubumi dan bergelar Adipati Gede Ing Kotawaringin. Hadiah yang paling berharga dari Sultan bagi Kiai Gede adalah dibangunnya sebuah masjid yang dijadikan sebagai pusat kegiatan-kegiatan kemasyarakatan bagi Kiai Gede dan para pengikutnya. Bersama para pengikutnya, yang waktu itu hanya berjumlah 40 orang, Kiai Gede kemudian membangun Kotawaringin dari hutan belantara menjadi sebuah kawasan permukiman yang cukup maju. Kalaupun wilayah Kotawaringin sekarang ini menjadi salah satu kota yang terbilang maju di Kalimantan, hal itu tidak dapat dipisahkan dari jasa besar Kiai Gede dan para pengikutnya. Kiai Gede membangun Sebuah Masjid yang bernama Masjid Kiai Gede. Mesjid ini menjadi saksi sejarah perkembangan Islam di Kotawarngin (Sulistiono, 2011).

\section{Budaya Oloh Salam}

Tidak ada petunjuk yang jelas kapan munculnya istilah oloh salam dalam budaya Dayak, akan tetapi dari berbagai sumber data dapat diduga bahwa munculnya istilah oloh salam dapat dilacak sejak awal masuknya Islam di Kalimantan sebagaimana pembentukan kampung lemu melayu yang didiami oleh orang Dayak yang telah masuk Islam, sedangkan kampung yang didiami oleh orang Kristen atau yang beragama helo disebut kampung lemu dayak. Inilah salah satu bentuk polarisasi sistemik yang dilakukan oleh 
kolonial di bumi Kalimantan (Kementrian Penerangan, 1953).

Tanda-tanda Islam di Kalimantan berdiaspora secara masif pada abad ke-1415 dikuatkan dengan data-data linguistik yang diutarakan oleh Collins (1990). Periode yang disebut juga "the age of commerce", terlihat di bandar-bandar Nusantara para pedagang Melayu menggunakan bahasa Melayu sebagai pengantar (Reid ,1988). Para pedagang itu adalah orang-orang yang beragama Islam. Tidak hanya pedagang lokal dari Banjar yang lebih dahulu masuk Islam yang banyak berperan dalam penyebaran Islam kepada masyarakat Dayak. Para sufi pengembara juga berperan menyebarkan agama Islam kepada para penguasa/kepala suku yang kemudian diikuti oleh rakyat mereka. Para sufi pengembara yang pernah singgah di tanah Dayak antara lain Datu Panghulu Tuan Pandak (Haji Ibrahim Muhammad Sadar) di Muara Teweh, Datu Nabe di Sampit, Syekh Basiri bin Sayidullah dan $H$. Abdurrahman bin H. Abdullah Bugis di Sampit, Datu Purbaya, Datu Kartasura,dan lain-lain (Al-Kumayi, 2011).

Sebagian besar suku Dayak yang memeluk agama Islam tidak lagi mengakui dirinya sebagai orang Dayak, tetapi menyebut dirinya sebagai orang "Melayu" atau orang "Banjar". Sedangkan orang Dayak yang tidak memeluk agama Islam kembali menyusuri sungai, masuk ke pedalaman di Kalimantan. Di Kalimantan Selatan misalnya mereka bermukim disekitar daerah Kayu Tangi, Amuntai, Margasari, Watang Amandit, Labuan Lawas dan Watang Balangan. Sebagian lagi terus masuk rimba. Orang Dayak yang memeluk agama Islam kebanyakan berada di Kalimantan Selatan dan sebagian Kotawaringin (Ukur, 1971). Dayak yang beragama Islam di Kalimantan Tengah tetap mempertahankan etnisnya sebagai orang Dayak, demikian juga bagi Dayak yang beragama Kristen. Agama asli suku Dayak di Kalimantan Tengah adalah
Kaharingan, yang merupakan agama asli yang lahir dari budaya setempat sebelum bangsa Indonesia mengenal agama pertama yakni Hindu. Karena Hindu telah meyebar luas di dunia terutama Indonesia dan lebih dikenal luas, jika dibandingkan dengan agama suku Dayak, maka Agama Kaharingan dikategorikan cabang agama Hindu.

Oloh salam di Kalimantan Tengah adalah sebutan internal orang-orang Dayak yang memeluk agama helo atau agama leluhur untuk menyebut saudara sesukunya yang telah masuk Islam. Fenomena semacam ini umum ditemukan di Nusantara, seperti penyebutan Cam Bani atau Cam Asalam bagi orang Campa yang telah masuk Islam. Sedangkan yang masih memeluk agama Hindu disebut Cam Jat (Cabaton,1981:222). Orang Islam di Malaysia disebut orang Melayu sedangkan orang Malaysia yang masih memeluk agama lama disebut orang asli. Istilah Oloh Salam yang dibedakan dengan Dayak tidak mengandung makna yang bersifat antropologis sebagai pembeda kelompok etnis, tetapi lebih bersifat sosio-religius.

Masyarakat Dayak yang telah memeluk agama Islam (Oloh Salam) ini masih terdapat sisa-sisa kepercayaan primitif yang tercampur dengan agama Islam. Terdapat kecenderungan pembentukan pola perilaku kehidupan sosial budaya Dayak Islam yang bersifat khas di berbagai dimensi kehidupan seperti dalam gawi belum berupa upacara kelahiran, pengobatan, perkawinan, sedekah laut; gawi matei berupa upacara kematian.

\section{Upacara Kelahiran}

Upacara kelahiran dalam budaya oloh salam dilakukan jika seorang ibu telah mengandung 3 bulan sampai menginjak hari kelahiran sejak itu dia sudah dihinggapi penyakit pantang. Misalnya dilarang keluar waktu senja, tidak boleh berurai rambut, dilarang memaku, tidak boleh makan yang pedas dan lain 
sebagainya. Sang suami pun berpantang pula, tidak boleh menebang pohon, menghunjam tiang apalagi membunuh binatang. Pantangan tersebut harus dilakukan bertujuan untuk melindungi sang bayi, baik yang masih dalam kandungan atau yang baru lahir, karena masih lemah agar tidak dapat diganggu oleh roh jahat.

Bila perempuan oloh salam hendak melahirkan, dilakukan Pembacaan doa secara Islam dilakukan dengan membakar kemenyan dan menabur-nabur beras kuning sebagai penjagaan diri untuk menolak roh-roh jahat yang akan mengganggu kelahiran bayi. Bayi yang baru lahir dimandikan dan dibersihkan, tali pusarnya dipotong dengan sembilu diatas uang perak, ringgit atau rupiah, setelah itu dibalut dengan seutas tali akar hutan. Ayah si bayi kemudian mengumandangkan adzan dan iqomat ditelinga kanan dan kiri secara bergantian. Menjelang umur bayi 7 hari, 40 hari bagi orang Dayak yang beragama helo, diadakan upacara tasmiah (Arab: tasmia" pemberian nama si bayi") yang dilakukan menurut kemampuan keluarga saja. Nama yang umumnya diberikan kepada bayi oloh salam merupakan gabungan nama Islam dan Dayak.

\section{Upacara Pengobatan}

Di wilayah aliran sungai Barito yaitu Muarateweh, Buntok, Puruk Cahu yang merupakan wilayah pemukiman Dayak Bakumpai yang merupakan sub Dayak Ngaju yang telah memeluk Islam, seni-seni tradisi singkretis Dayak Islam hingga kini masih dapat dilihat seperti pada ritual Badewa. Ritual Badewa atau berdewa dalam tradisi Dayak Bakumpai dilakukan dengan maksud-maksud yang diyakini sebagai media untuk menyembuhkan orang sakit dengan mengundang berbagai macam dewa yang bersemayam di berbagai aliran sungai maupun tempat-tempat keramat yang terdapat di berbagai penjuru di Kalimantan Tengah. Pada permulaan upacara Badewa nama Allah, nabi dan sahabat disebutkan; meskipun demikian disebut juga jin-jin hutan, gunung, sungai, arwah leluhur yang telah meninggal, jin dari seberang dan terutama para dewa dan roh pelindung.

Unsur-unsur Islam pada upacara tersebut terdapat pada ucapan salam pembuka secara Islam kepada salah seorang sahabat nabi Muhammad SAW dan kepada Nabi Khidir. Nabi Khidir dalam budaya Dayak dianggap sebagai penguasa air dan menikah dengan seorang Putri Batara Gangga di negeri bawah laut, putri yang dilahirkan kemudian menjelma di bumi sebagai Putri Junjung Buih, Nabi Khidir menjadi ayahanda ajaib mertua Suryanata. Beliaulah yang menyamar sebagai seorang pengembara berjubah putih yang mengawinkan Putri Junjung Buih dengan Suryanata.

\section{Upacara Perkawinan}

Upacara perkawinan didahului dengan lamaran (hakumbang auh) yang dilakukan oleh wakil dari pihak laki-laki kepada keluarga pihak perempuan. Jika niat melamar ini diterima maka diresmikan dalam pertunangan dengan penyerahan batu pisek sejumlah uang dan pakaian sinde mendeng atau seperangkat pakaian perempuan lengkap hal ini lazim pula disebut kawin gantung. Dilanjutkan dengan pembicaraan pembuatan surat nikah disebut surat pelek lengkap dengan syarat dan sanksi yang harus dilakukan apabila terjadi sesuatu di kemudian hari. Syaratsyarat yang tercantum dalam surat pelek adalah semua permintaan pihak perempuan yang harus dipenuhi pihak laki-laki. Sedangkan sanksi berisi kewajiban untuk mengembalikan seutuhnya semua syarat dalam surat pelek jika si perempuan meminta cerai dari suami. Sebaliknya suami tidak dapat meminta kembali jika 
sang suami yang menceraikan istrinya. Sedangkan sanksi berisi kewajiban untuk mengembalikan seutuhnya semua syarat dalam surat pelek jika si perempuan meminta cerai dari suami. Sebaliknya suami tidak dapat meminta kembali jika sang suami yang menceraikan istrinya. Pada hari yang telah disepakati, kedua penganten melaksanakan ijab kabul secara Islam di hadapan penghulu di KUA dengan mas kawin alquran dan seperangkat alat sholat.

\section{Upacara Sedekah laut}

Upacara sedekah laut lazim dilakukan oleh penduduk yang berada di pesisir laut, seperti di Sampit dan Samuda.Upacara ini biasanya dilakukan oleh para nelayan untuk memberikan sedekah laut kepada dewa laut yang disebutnyamapanre tasi. Hal ini dimaksudkan agar mereka mendapatkan hasil ikan yang banyak dalam melaut, karena dewa-dewa laut sang empunya ikan sudah diberikan bagian.Doa yang dipanjatkan dalam acara mapanretasi merupakan perpaduan antara mantra dan doa-doa Islam.

\section{Upacara Saparan}

Bulan sapar bagi oloh salam adalah bulan di mana banyak kejadian orang dimakan oleh buaya di sungai, sehingga harus diadakan satu ritual menolak bala dengan mandi bersama di sungai disebut juga mandi sapar. Anak-anak lelaki dan perempuan di Sampit biasanya melakukan mandi sapar dengan cara berenang menyebrang sungai Mentaya tanpa menggunakan pelampung. Anak-anak berani melakukan ini karena di celana berenangnya dilekatkan daun sawang yang telah ditulisi kalimat Basmalah dalam huruf Arab. Daun sawang adalah daun keramat yang ditanam di atas kuburan sebagai penolak bala dari roh-roh jahat orang yang telah meninggal, juga berfungsi sebagai penanda wilayah pemakaman. Daun sawang yang telah ditulisi Basmallah merupakan daun yang dianggap memiliki kekuatan magis sebagai penangkal bala terutama bahaya dari terkaman buaya di sungai.

\section{Upacara Kematian}

Tradisi dalam masyarakat Dayak jika mendengar berita kematian warganya mereka akan segera menghentikan pekerjaan yang sedang mereka lakukan, segera mendatangi rumah duka, untuk memberikan dukungan moral bagi keluarga yang ditinggalkan. Mereka datang dengan membawa sumbangan duka berupa hasil bumi mereka sendiri. Di rumah duka mereka mendekati dan melihat wajah jenazah untuk terakhir kali, karena melakukan hal ini diyakini akan mendapat pahala. Jenazah diletakkan di tengahtengah rumah dan dikelilingi kaum kerabat dan keluarga, sebelum dimandikan. Karena setelah dimandikan secara Islam dan dikafani jenazah sudah tidak boleh dibukabuka lagi untuk dilihat oleh para pelayat.

Peti jenazah disebut 'tabla' dibuat saat itu juga secara bergotong royong(Jones, 2008). Peti mati dibuat dari batang pohon yang dibelah dua dan dibagian tengah dikerok untuk tempat meletakkan jenazah. Sejalan dengan berkurangnya pohon-pohon besar, maka peti jenazah sekarang dibuat dari papan-papan yang telah dihaluskan dan berbentuk kotak persegi panjang. Setelah peti mati selesai dibuat, diletakkan di sebelah jenazah menunggu sampai saatnya jenazah dimasukkan ke dalam peti mati, untuk dibawa ke masjid terdekat untuk dishalatkan terlebih dahulu sebelum dimakamkan.

\section{Toleransi dan unsur Islamdalam Budaya Dayak}

Oloh Salam tetap diakui dan dihormati sebagai saudara oleh saudara sesukunya yang masih beragama helo atau Kaharingan. Hal ini dapat dilihat, misalnya 
bila orang Kaharingan mengadakan upacara adat, oloh salam juga diundang dan disediakan tempat maupun peralatan makan yang khusus. Begitu juga hewan ternak (sapi dan ayam) yang digunakan dalam suatu pesta disembelih dan dimasak sesuai ajaran Islam. Jika oloh salam menjadi tamu dan menginap di rumah-rumah orang Kaharingan di pedalaman, maka akan diminta untuk mendoakan mereka secara Islam, karena mereka merasa nyaman jika dibacakan do'a oleh oloh salam.

Orang Dayak yang beragama Kaharingan secara fitrah memiliki unsur Islam dalam kepercayaan lokal mereka seperti adanya Tuhan satu bersifat monoteistis sebagai Ranying Mahatala yang memiliki kekuasaan tunggal dalam menciptakan langit dan bumi beserta isinya (Rafiq, 2011). Ranying berasal dari bahasa sanskrit yang berarti cahaya. Sedangkan istilah Mahatala merupakan istilah yang berasal dari kata Maha yang artinya Paling dan Allah Ta'ala yang Tinggi di ambil dari bahasa Arab. Mahatala memiliki beberapa roh baik sebagai malaikat yang bertugas menyejahterakan dan menjaga keselamatan manusia yaitu Raja Uju Hakanduang pembawa ajaran Tuhan, Raja Tunggal Sangumang membawa rejeki, Rawing Tempun Telon mengantar roh ke surga, Raja Sambung Maut pencabut nyawa, Raja Entai Nyahu penjaga kuburan. Tokoh mitologi Nyai Siti seperti disebutkan dalam kitab Panaturan berasal dari Bahasa Arab yaitu Siti Hawa sebagai salah satu cikal bakal manusia yang menempati bumi (Macdonell, 1924).

\section{Pola Keruangan Budaya Oloh Salam}

Ruang merupakan tempat interaksi masyarakat dalam kaitannya dengan kehidupan social dan kemasyarakatannya, dalam hal ini ruang bias dikatakan sebagai wadah untuk menyalurkan berbagai aktivi tas baik sosial, ekonomi, dan budaya masyarakat dimana terjadi percampuran kegiatan, strata sosial, dan budaya masyarakatnya (Jayadinata, 1999). Tidak jauh berbeda dari definisi ruang diatas, Amos Rapoport dalam kajian arsitektur lingkungan dan perilaku juga mengungkapkan pengaruh ruang terhadap perilaku manusia yaitu fungsi atau pemakaian dari ruang tersebut yang dirancang untuk memenuhi suatu fungsi dari tujuan tertentu, maupun untuk memenuhi fungsi yang fleksibel. Sehingga ruang dapat saja timbul dari aktifitas suatu masyarakat dengan tujuan dan fungsi tertentu yang sifatnya temporer atau sementara, dimana setelah aktifitas atau kepentingan masyarakat telah usai maka ruangan yang terbentuk hilang. Masih menurut Rapoport (1973) ruang terstruktur melalui berbagai cara dengan skala yang berbeda-beda mulai dari lingkup individu sampai pada cakupan yang luas yaitu ruang wilayah terorganisasi. Hubungan manusia dengan lingkungannya tidak bersifat statis akan tetapi bersifat dinamis. Hal ini berarti bahwa perubahan kegiatan manusia akan mengubah tatanan ruang maupun makna ruang didalamnya.

Jika dilihat dari definisi ruang yang merupakan akselerasi dari budaya lokal, dimana ruang yang terbentuk pada permukiman masyarakat tradisional biasanya merupakan proyeksi imajiner dari budaya yang ada. Maka perlu diungkapkan juga wujud budaya dalam konteks penciptaan tatanan ruang permukiman menurut J.J. Honogman dalam Koentjaraningrat (1981)yaitu:

1. Wujud sebagai system budaya atau adat istiadat sebagai kompleks dari ideide, nilai-nilai, norma-norma, peraturan, dan sebagainya. Wujud kebudayaan ini merupakan wujud ideal dari kebudayaan. Sifatnya abstrak dan tidak dapat diraba atau dirasakan secara kasat mata, karena hanya ada dalam alam pikiran masyarakat dimana kebudayaan yang bersangkutan hidup. 
2. Wujud sebagai system social yang kompleks suatu aktifitas atau tindakan yang berpola dari manusia dalam masyarakat, wujud kebudayaan ini bersifat konkret, bias diobservasi, dan bisa didokumentasi.

3. Wujud sebagai system kebudayaan fisik sebagai benda-benda hasil kebudayaan manusia yang merupakan seluruh total hasil fisik dari aktifitas serta karya manusia dalam masyarakat. Sehingga memilki sifat paling konkret, dan benda-benda atau hal yang dapat diraba, dilihat dan didokumentasi.

Dalam konteks relasi linear antara budaya dan ruang, dimana tatanan ruang permukiman yang terbentuk dapat dikatakan sebagai proyeksi budaya masyarakat setempat, maka dalam kerangka pendekatan studi perilaku yang diungkapkan oleh Rapoport (1977) menekankan bahwa latar belakang manusia seperti pandangan hidup, kepercayaan yang dianut, nilai-nilai dan norma-norma yang dipegang akan menentukan perilaku seseorang yang tercermin dalam cara hidup dan peran yang dipilihnya dimasyarakat. Lebih lanjut, konteks cultural dan social ini akan menentukan system aktifitas atau kegiatan manusia. Cara hidup dan system kegiatan akan menentukan macam dan wadah bagi kegiatan tersebut. Wadah tersebut berupa ruang-ruang yang saling berhubungan dalam waktu tertentu. Penegasan identitas budaya dalam ruang komunal merupakan bentuk dari identitas budaya (culturalidentity) atau dalam hal ini adalah kearifan lokal(genious loci).

Pola keruangan budaya Oloh Salam didapat dari overlay peta perkembangan masyarakat Dayak muslim. Perkembangan islam diperoleh dari peta administrasi yang dioverlay dengan persebaran penduduk beragama islam.
Berdasarkan hasil overlay peta, dapat diketahui bahwa persebaran masyarakat Dayak Islam (Oloh Salam) meliputi wilayah: Muara-teweh, Buntok, Puruk Cahu yang merupakan wilayah pemukiman Dayak Bakumpai, sekitar daerah aliran sungai Mentaya di Sampit, Kapuas Barat, danKotawaringin Timur. Berdasarkan teori Pola keruangan, budaya Oloh Salam di Kalimantan Tengah mengikuti pola memanjang sungai untuk wilayah aliran sungai Barito. Pola memanjang pantai terdapat di daerah Sampit.

Pola keruangan budaya Oloh Salam di Kalimantan Tengah membentuk pola linear di sepanjang alur sungai dan pantai. Pola yang terbentuk ini dipengaruhi oleh kondisi fisik daerahnya yaitu topografi wilayah. Permukiman penduduk sangat tergantung dengan kondisi lingkungan, seperti memanjang aliran sungai, memanjang jalan, dan memanjang jalan kereta api (Sumadi, 2010). Hal ini sesuai konsep geografi yaitu konsep pola berkaitan erat dengan susunan bentuk atau persebaran fenomena dalam ruang di muka bumi, baik fenomena yang bersifat alami atau fisis. Seperti pola aliran sungai, pola persebaran vegetasi, jenis tanah dan pola curah hujan di daerah tertentu, ataupun fenomena sosial budaya seperti pola permukiman, pola persebaran penduduk, pola pendapatan, pola mata pencaharian, jenis rumah tempat tinggal dan sebagainya.

Pola memanjang sungai dan pantai yang terbentuk ini membuktikan bahwa, persebaran Islam dimulai di daerah pesisir pantai oleh para ulama dari Jawa maupun para saudagar asing melalui jalur perniagaan. Dari jalur pantai kemudian berlayar melalui jalur sungai untuk memperluas persebaran agama Islam hingga tersebar ke pelosok-pelosok daerah. 


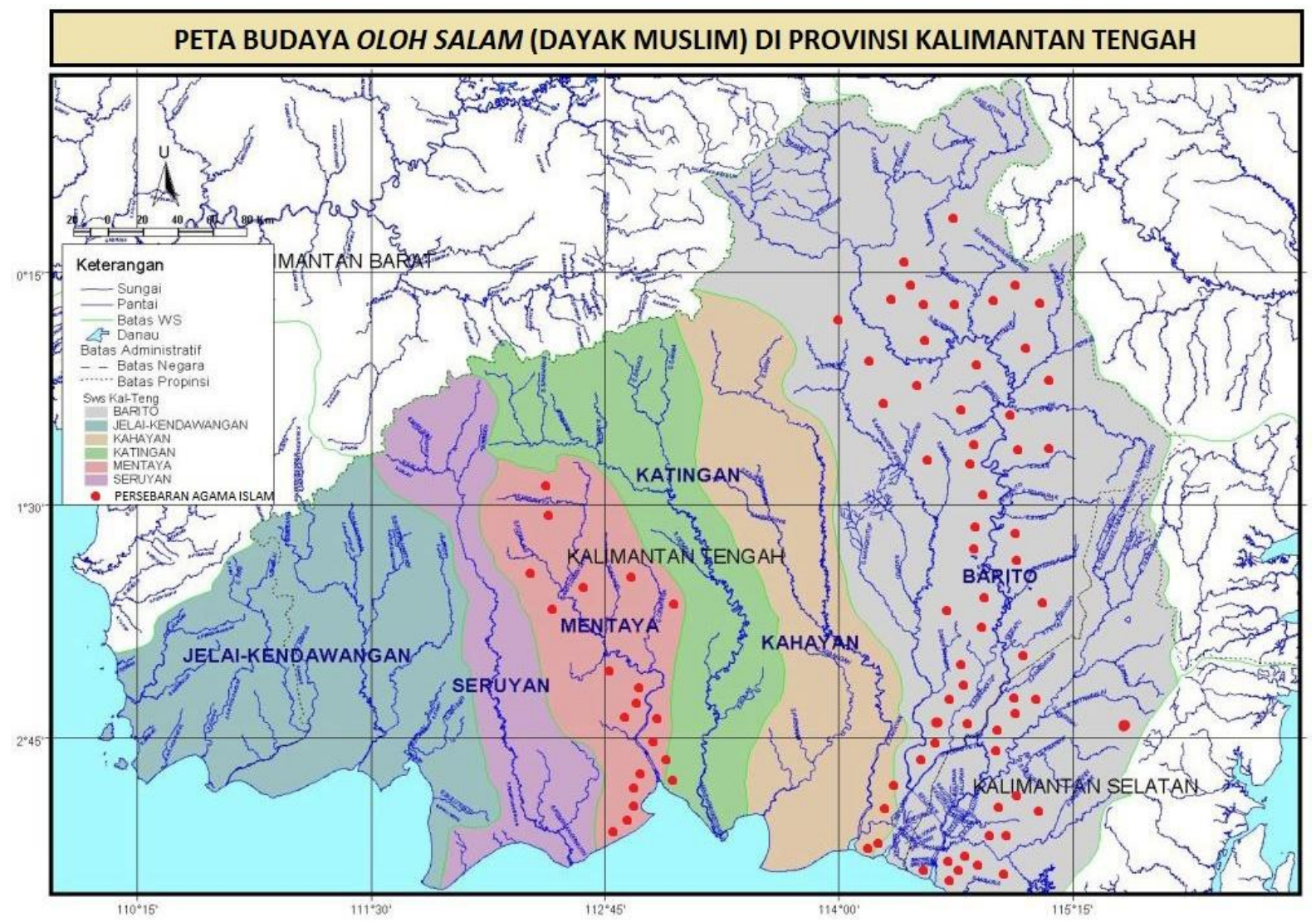

Gambar 1. Peta Budaya Oloh Salam di Provinsi Kalimantan Tengah

\section{KESIMPULAN}

Aktualisasi nilai-nilai Islam dalam budaya Dayak terwujud dalam Oloh Salam dan pola toleransi dalam interaksi sosial melalui proses yang bersifat persuasif dan bersahabat yang berlangsung dari generasi ke generasi terjadi secara alamiah karena pada hakekatnya nilai-nilai Islam telah ada dalam budaya Dayak.

Hasil penelitian menunjukkan bahwa pola keruangan budaya Oloh Salam membentuk pola memanjang sungai dan pantai. Hal tersebut membuktikan bahwa, persebaran Islam dimulai di daerah pesisir pantai oleh para ulama dari Jawa maupun para saudagar asing melalui jalur perniagaan. Mereka menyebar dari jalur pantai kemudian berlayar melalui jalur sungai untuk memperluas persebaran agama Islam hingga tersebar ke pelosokpelosok daerah.

\section{DAFTAR PUSTAKA}

Adam, A. W. (2007). Pelurusan Sejarah Indonesia. Yogyakarta: Penerbit Ombak

Al-Kumayi, S. (2011). Islam bubuhan Kumai: perspektif varian awam, nahu, dan hakekat. Pustaka Zaman.

Anonim. (2007). Panaturan. Palangka Raya: Majelis Besar Agama Hindu Kaharingan Pusat.

Aspinall, P. (1993). Aspects of spatial experience and structure. Companion to Contemporary Architecture Thought. Rutledge, London, 337-345.

Buseri, K. (2009). Sepintas Masuknya Islam Di Borneo. Artikel. 28 Desember 2009

Cabaton. (1981). Orang Cam Islam di Indocina Perancis dalam Kerajaan Campa. (E.F. D'extreme - Orient, Penyunt.) Jakarta: PN Balai Pustaka.

Collins, J. T. (1990). Bibliografi dialek Melayu di pulau Borneo. Dewan Bahasa dan Pustaka, Kementerian Pendidikan Malaysia. 


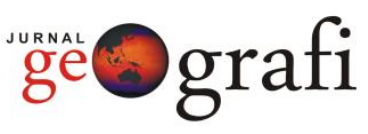

Danby, M. (1993). Privacy as a culturally related factor in built form. Companion to Contemporary Architectural Though. London, 138-139.

Darmadi, H. (2017). Dayak Asal-Usul dan Penyebarannya Di Bumi Borneo (1). Sosial Horizon: Jurnal Pendidikan Sosial, 3(2), 322-340.

De Graaf, H. J., \& Pigeaud, T. G. T. (1974). De eerste Moslimse vorstendommen of Java.

Farmer, B., \& Louw, H. J. (Eds.). (1993). Companion to contemporary architectural thought. Taylor \& Francis.

Hamka. (1982). Sejarah Masuknya Islam di Indonesia. Jakarta: Rajawali Pustaka

Jayadinata,J. T. (1999). Tata Guna Tanah Dalam Perencanaan Pedesaan Perkotaan dan Wilayah. Edisi 3. Bandung:ITB.

Jones, R. (2008). Loan-Words in Indonesian and Malay. Jakarta: Yayasan Obor Indonesia.

Kartodirdjo, S. (1975). Sejarah Nasional Indonesia III. Jakarta: Departemen Pendidikan dan Kebudayaan.

Kementrian, R. I. (1953). Republik Indonesia: Provinsi Kalimantan. Jakarta.

Koentjaraningrat. (1981). Pengantar Ilmu Antropologi. Jakarta. Rineka Cipta.

Kompasiana. (2013). Asal Usul Suku Dayak Kalimantan.

https://www.kompasiana.com/sama rindatourism/asal-usul-suku-dayakkalimantan_5529c1d6f17e61b123d623c d

Locher, GW. (1978). Transformation and Tradition, and Other Essays, KITLV Translation Series 18. The Hogue Martinus Nijhoff.

Macdonell, A. A. (1924). A practical Sanskrit dictionary with transliteration, accentuation, and etymological analysis throughout. Motilal Banarsidass Publ.

Abduh, M. (1985). Sejarah Indonesia Madya. IKIP Ujung Pandang

Nisa, R. (2016). Sejarah Islam di Kalimantan. Makalah.

Rafiq, A. (2014). Eksistensi agama lokal di Indonesia: Agama Kaharingan di masyarakat adat Dayak Meratus.
Available at http://jurnal.unimed.ac.id/2012/index.php/geo e-ISSN: 2549-7057 | p-ISSN: 2085-8167

(Disampaikan pada Diskusi Publik Agama dan Budaya Lokal, di UIN Sunan Kali Jaga, 02 Desember 2014).

Rafiq, A. (2013). Relasi Dayak-Banjar dalam Tutur Masyarakat Dayak Meratus. AlBanjari: Jurnal Ilmiah Ilmu-Ilmu Keislaman, 12(1).

Rapoport, A. (1973). Some Perspektive on Human Use and Organization Of Space. Thirty Three Papers ini EnviromentalBehaviour Research. NewCastle: TheUrban InternationalPress.

Rapoport, A. (1977). Human Aspect of Urban Form. Oxford: Pergamon Press

Ras, J. (1968). Hikajat Bandjar: A Study in Malay Historiography. The Hague: Martinus Nijhoff.

Reid, A. (1988). Southeast Asia in the Age of Commerce 1450-1650. New Haven: Yale University Press.

Samadhi, T. N. (2004). Perilaku dan Pola Ruang. Penerbit Lembaga Penelitian dan Pengabdian Masyarakat Intitut Teknologi Nasional, Malang Jawa Timur.

Sasongko, I. (2005). Pembentukan Struktur Ruang Permukiman Studi Kasus Desa Puyung-Lombok Tengah. DIMENSI (Journal of Architecture and Built Environment), 33(1).

Sulistiono, B. (2011). Seminar Pemetaan Arkeologi Islam Nusantara. Pekanbaru.

Sumadi. (2010). Perkembangan Pemikiran dan Kajian Geografi. Bandar Lampung: FKIP Universitas Lampung.

Tuan, Y. F. (1977). Space and place: The perspective of experience. $\mathrm{U}$ of Minnesota Press.

Ukur, F. (2000). Tuaiannya sungguh banyak: sejarah Gereja Kalimantan Evanggelis sejak tahun 1835. BPK Gunung Mulia. 